\title{
Trajetória sociocultural e histórica do badminton em Montes Claros (MG)
}

\author{
Sociocultural and historical trajectory of badminton in Montes Claros, Minas Gerais, Brazil
}

Emilly Thais Gonçalves Dias, Guilherme Carvalho Vieira, Ester Liberato Pereira

Universidade Estadual de Montes Claros (Unimontes), Montes Claros/MG, Brasil

\author{
HISTÓRICO DO ARTIGO \\ Recebido: 29 março 2020 \\ Revisado: 23 julho 2020 \\ Aprovado: 27 julho 2020
}

\section{PALAVRAS-CHAVE:}

Badminton; História; Esporte.

\section{KEYWORDS:}

Badminton; History; Sport.

\section{RESUMO}

INTRODUÇÃO: O presente artigo concerne a uma pesquisa inserida no campo da História do Esporte e interrelacionada com os estudos socioculturais.

OBJETIVO: Investigar a emergência da prática esportiva do badminton na cidade de Montes Claros, localizada no Norte de Minas Gerais, desde as suas primeiras manifestações até a sua ascensão na cidade.

MÉTODOS: Foi concretizada uma investigação com base em fontes documentais e impressas, como jornais locais que noticiaram vários acontecimentos relacionados ao badminton em Montes Claros, além de documentos impressos fornecidos por alguns professores e profissionais de badminton presentes na cidade. Tais fontes foram submetidas à análise documental.

RESULTADOS: Os primeiros vestígios do badminton em Montes Claros datam de 2007. O badminton contou com diferentes periódicos locais como cooperadores, abordando distintos episódios na região e permitindo a conquista de espaço junto ao panorama sociocultural norte-mineiro. A partir desse movimento, surge a Associação de Badminton de Montes Claros ( $\mathrm{BBdMOC}$ ) com o objetivo social de proporcionar e incentivar a prática do badminton e do paradesporto (parabadminton) e de sustentar a oportunidade de uma prática esportiva saudável. Com a sua ampliação, adveio a concepção da Equipe de Badminton da Associação Atlética Banco do Brasil (AABB), com um caráter esportivo competitivo, resultando na contribuição para o desenvolvimento da prática na região.

CONCLUSÃO: Localizaram-se indícios das primeiras manifestações e do incremento do badminton em Montes Claros, bem como do quanto o acesso a essa prática cultural foi ampliado no transcorrer dos últimos anos no município, colaborando para o desenvolvimento cultural local. Desvelaram-se, ainda, importantes colaboradores que fizeram e seguem fazendo com que o badminton se amplie e seja apreciado, o que faz com que este estudo consista em um pilar para pesquisas científicas futuras em função do baixo número de artigos históricos e socioculturais a respeito deste esporte.

\section{ABSTRACT}

BACKGROUND: This paper deals with research inserted in the field of Sport History and interrelated with sociocultural studies.

OBJECTIVE: To investigate the emergence of badminton in the city of Montes Claros, located in the north of Minas Gerais, from its first manifestations to its rise in the city.

METHODS: An investigation was carried out in documentary and printed sources, such as local newspapers that reported various events related to badminton in Montes Claros, as well as printed documents provided by some badminton teachers and professionals present in the city. Such sources were submitted to documentary analysis.

RESULTS: The first vestiges of badminton, in Montes Claros, date from 2007. Badminton had different local newspapers as cooperators for this practice, addressing different episodes in the region and allowing the conquest of space within the socio-cultural panorama of Minas Gerais. From this movement, the Montes Claros Badminton Association ( $A B d M O C$ ) emerges, with the social objective of providing and encouraging the practice of badminton and parasports (parabadminton), in addition to sustaining the opportunity for a healthy sports practice. Then, with its expansion, the conception of the Badminton Team of the Athletic Association Banco do Brasil (AABB) was carried out, with a competitive sporting character, resulting in the contribution to the development of the practice in the region.

CONCLUSION: Evidence of the first manifestations and increase of badminton in Montes Claros were identified, as well as the extent to which access to this cultural practice has been expanded over the last few years in the city, contributing to the local cultural development. Important collaborators who made and continue to make badminton expand and be appreciated have also been unveiled, which makes this study a pillar for future scientific research, due to the low number of historical and socio-cultural articles about badminton. 


\section{INTRODUÇÃO}

O presente artigo concerne a uma pesquisa que se encontra inserida no campo da História do Esporte e inter-relacionada com os estudos socioculturais. Nesse âmbito, segundo Melo e Fortes (2011), o esporte tem a capacidade de ceder uma visibilidade de relações sociais mais sutis, sobretudo quando incorporado à abordagem cultural da história, mais especificamente à história do tempo presente. Esta, em consonância com Delgado e Ferreira (2014), consiste em acontecimentos que ainda estão sendo realizados, ou seja, em fatos que estão em constante atualização, ampliando, a priori, a possibilidade das fontes da visão acerca do esporte.

Sob essa ótica, este estudo aborda um processo de desenvolvimento histórico da prática do badminton na cidade de Montes Claros, situada na região Norte do estado de Minas Gerais. Buscou-se abranger, desde os seus vestígios elementares, até seu aporte para o desenvolvimento cultural norte-mineiro. Dessa forma, tem-se ciência de que se trata de um cenário em que um esporte de raquete, que exige agilidade e rapidez, encontra-se, como apontado pela literatura, entre as atuais ofertas de prática esportiva para pessoas com deficiência, ou seja: o badminton tem sido amplo aliado à inclusão e ao desenvolvimento global dessas pessoas (OLIVEIRA; GONÇALVES; SEABRA JUNIOR, 2017). Além disso, considera-se, aqui, o que fora já registrado por Souza, Raasch e Maria (2017), conforme os quais, o emprego do badminton nas aulas de Educação Física Escolar pode proporcionar influências e benefícios.

Nesse viés, Melo e Bittencourt (2013) explicitam a necessidade do estudo histórico e da relação com a sociedade. Ademais, diante de um cenário que privilegia os grandes centros urbanos, emerge a viabilidade de análises no que tange ao esporte nos contextos regionais. Perante esse panorama, nasce a presente investigação, que apresenta o contexto geral do badminton em relação ao seu desenvolvimento regional e à sua apropriação no contexto escolar.

De acordo com Machado, Souza e Silva (2019), existe uma hegemonia na prática de determinados esportes em detrimento de outros, em especial no âmbito escolar. Nessa linha, os autores apresentam os fatores que dificultam a expansão dos esportes de raquete, entre os quais está a falta de divulgação destas atividades, além de privilégios para os esportes coletivos considerados como o "quarteto fantástico": futebol/futsal, vôlei, basquete e handebol. Vale salientar que, no que diz respeito à pesquisa histórica sobre as modalidades de esporte de raquete, também se mostra escassa a produção.

Em contrapartida, a averiguação de Corrêa, Freitas e Silva (2019) propõe a inserção dos esportes de raquete nas aulas de Educação Física Escolar, porém com inovação e criatividade. Evidencia-se que os conteúdos de esportes de raquete apresentam uma boa aceitação no contexto escolar se comparados aos conteúdos hegemônicos e dominantes da Educação Física.

É mister enfatizar que o badminton se traduz como um esporte de quadra, dividido por uma rede, praticado com uma raquete e uma peteca, denominada de 'volante' ou 'birdie'. Ocorre de forma simples, em duplas ou em duplas mistas. Originou-se na Índia, batizado de poona, por volta de 1.800 (JUNIORS, 2019).
No entanto, houve traços dessa manifestação esportiva na civilização grega, na Europa e na Ásia, onde foi denominada de "tamborete e peteca". Passou a ser semeada na Europa, por meio de oficiais ingleses que prestavam serviços na colônia da Índia, a qual também passou a apreciar a prática. Em 1870, em conformidade com Kath (2014), a atividade passou a ser chamada de badminton em decorrência do fato de ser praticada na Propriedade de Badminton, pertencente ao Duque de Beaufort's, em Gloucestershire, na Inglaterra, com regras específicas.

No século XIX, a prática ganhou visibilidade e disseminou-se na América, na Ásia e na Europa. Consoante a Confederação Brasileira de Badminton ( $C B B d$ ), este é um jogo acelerado, que abarca quadra, peteca e raquete. É considerado o segundo esporte mais praticado no mundo, apesar de, no Brasil, não representar, ainda, um exercício muito difundido (CBBd, 2015).

Trata-se de um desporto popular em países do Oriente, como Singapura, Índia, Indonésia, China, Paquistão, Japão e Tailândia. No Brasil, devido à carência de literatura científica acerca do esporte, por meio da qual se justifica este estudo, há muito ainda a se compreender, sob uma perspectiva histórica e sociocultural, no que concerne à prática em análise. A despeito disso, a primeira competição oficial ocorreu, na Taça São Paulo, em 1983 (CBBd, 2015).

A primeira medalha brasileira foi conquistada em 2007, nos Jogos Pan-Americanos do Rio de Janeiro, e testemunhada por um dos sócios-fundadores da Associação de Badminton de Montes Claros (ABdMOC). Identificou-se, em Minas Gerais, um amplo desenvolvimento da atividade em pesquisa, especialmente a partir de 2016, quando foi fundada a Federação Desportiva de Badminton de Minas Gerais (FDB-MG). Três anos depois, em 2019, Minas passou a filiar-se à CBBd (CBBd, 2019). Nota-se, dessa forma, como o processo de desenvolvimento da prática é, de fato, recente no estado.

Em Montes Claros, da mesma maneira, a promoção do badminton como um esporte em disseminação mostra-se bastante atual, e, paulatinamente, muitas pessoas passam a vivenciar essa atividade que, assim como outras manifestações corporais, apresenta muitos benefícios para a saúde. Destarte, os grupos oficialmente registrados e existentes na cidade, hoje, são: Associação de Badminton de Montes Claros ( $A B d M O C)$ e Equipe de Badminton da Associação Atlética Banco do Brasil (AABB). Membros dessas equipes, além de conduzirem seu espaço e suas atividades, proporcionam eventos com o intuito de promover essa prática esportiva na região (GOMES, 2018).

Cumpre trazer à tela que as abordagens atuais de literatura científica acerca do badminton centram-se, essencialmente, em discussões sobre treinamento e iniciação esportiva (SOUZA; SILVA; MOREIRA, 2016). Devido a essa escassez de estudos socioculturais, reforça-se a relevância deste trabalho, uma vez que, segundo Barroso e Darido (2006), o esporte denota-se como um fenômeno sociocultural, considerado patrimônio da humanidade, que sofre manutenção e transformações até o momento atual.

É no presente panorama que desponta o objetivo deste estudo, o qual tem, por finalidade, investigar a emergência da prática esportiva do badminton na cidade de Montes Claros, localizada no Norte de Minas Gerais, desde as suas primeiras manifestações até a sua ascensão no município. Nesse contexto, cabe assinalar que, como postula Goellner et al. (2010), o esporte serve de análise para as relações da sociedade. 


\section{MÉTODOS}

A pesquisa contou com revisão narrativo-histórica, imbricada na história do tempo presente, o que possibilitou uma ampliação do uso das fontes. Além disso, foi realizada uma revisitação bibliográfica, pautada em artigos, monografias, dissertações, teses e livros. Nessa direção, foram examinados o Repositório Institucional e a Biblioteca da Universidade Estadual e de Montes Claros (Unimontes), por abarcarem desde trabalhos de conclusão de curso até dissertações e teses produzidas nesta instituição, a qual é referência na produção científica em diversas áreas do conhecimento, em uma ampla região que abrange, atualmente, uma extensão correspondente a $40 \%$ da área total do estado.

Ainda foi consultada a Biblioteca Digital de Teses e Dissertações, visto que esta é mantida pelo Instituto Brasileiro de Informação em Ciência e Tecnologia e congrega, em um só portal de busca, teses e dissertações defendidas em todo o país e por brasileiros no exterior. Também foram examinadas as bases Scientific Electronic Library Online (Biblioteca Científica Eletrônica On-line - SciELO), por ser direcionada para a publicação de artigos científicos desenvolvidos, notadamente, em países da América Latina e do Caribe, e, finalmente, a base dos Periódicos CAPES, porquanto oferece acesso a textos completos e de artigos selecionados de mais de 21.500 revistas nacionais e internacionais. Os descritores aplicados foram "História", "Badminton" e "Sociedade".

A investigação, quanto à natureza da coleta de dados, é documental. Para interpretar as fontes selecionadas, foi realizada uma análise documental, a qual favorece a observação do processo de maturação ou de desenvolvimento de indivíduos, grupos, conceitos, conhecimentos, comportamentos, mentalidades, práticas, entre outros. Para o levantamento de informações, foram empreendidas análises documentais em fontes impressas e digitalizadas nos acervos da Associação de Badminton de Montes Claros ( $\mathrm{BBdMOC}$ ) e da Associação Atlética Banco do Brasil (AABB), compostos por: a) cartazes de eventos; b) documentos on-line; c) documentos impressos; d) fotos dos eventos; e) quadras; f) uniformes e g) medalhas. Ainda foi efetuada coleta de fontes nos sites da Confederação Brasileira de Badminton (CBBd), da Associação de Badminton de Montes Claros (AbdMoc) e da Associação Atlética Banco do Brasil (AABB). No que diz respeito à natureza da coleta de dados - histórica e documental -, esta classificou-se como de caráter exploratório, ao buscar verificar possíveis colaboradores locais da prática do badminton na cidade de Montes Claros, bem como o público para o qual a prática se destinava.

A fim de interpretar as fontes coletadas, procedeu-se à organização do material obtido em pastas com palavras-chaves para a sua identificação. Foi executada uma análise documental, a qual possibilitou o cruzamento com a literatura científica e favoreceu a observação do processo de desenvolvimento de indivíduos, conceitos, comportamentos e prática no contexto específico de Montes Claros. Nessa via, de acordo com os termos propostos por Pimentel (2001) e Bacellar (2008), a análise documental preconiza, em um primeiro momento, o fichamento das fontes; em seguida, suas análises propriamente ditas e, por fim, um cruzamento desse corpus documental, admitindo cunhar significados acerca do objeto de estudo.
Nessa etapa, ainda são concretizadas a compilação e a codificação do material, conforme os objetivos indicados. Neste estágio do estudo, foram feitas a leitura do material levantado e a triagem das informações qualitativas e quantitativas para posteriormente se passar à análise das fontes. Para o desenvolvimento desta apreciação, a metodologia recomendada é o paradigma indiciário, o qual propicia uma análise intensa do que foi coletado. $O$ instrumento do saber indiciário constitui uma noção complexa, que assinala, em geral, a "capacidade de, a partir de dados aparentemente negligenciáveis, remontar uma realidade complexa não experimentável" (GINZBURG, 1989, p. 179).

Assim, a pesquisa foi desenvolvida em partes, por meio das quais, expõe-se, inicialmente, uma conjuntura sociocultural e político-econômica da cidade de Montes Claros/MG no período de fundação da ABdMOC. São abordados fatores básicos, acontecidos a partir da fundação da $\mathrm{ABdMOC}$, que contribuíram para a ascensão dessa prática esportiva na cidade.

Como contexto sociocultural e político-econômico de Montes Claros na década de 2010, tem-se a sede do município de Montes Claros, considerada polo de desenvolvimento do Norte de Minas Gerais, cumprindo clara influência sobre as demais cidades da região em virtude da importante função que exerce como núcleo urbano comercial e de prestação de serviços, além de parque industrial (PREFEITURA, 2010). A categoria de polo centralizador da região tem incitado a constante emergência de estabelecimentos industriais, comerciais e de serviços na cidade, que atua como integrante da Região Norte e Nordeste do estado, a qual inclui as mesorregiões Norte e Vale do Jequitinhonha. Essas localidades ainda não possuem conexão econômica significativa com as demais. Apesar disso, nos últimos anos, vêm sendo desenvolvidas políticas públicas com a finalidade de minimizar essas dificuldades.

Grandes empreendimentos têm sido trazidos para a região em função da adequada formação dos profissionais e da mão de obra qualificada existente. Nesse território, está centrado, ainda, um Centro Tecnológico com amplo potencial de formação de profissionais.

Ao longo da década de 2010, o poder público concentrou suas estratégias em buscar integrar a região à lógica de comércio e mercado por meio da ampliação da infraestrutura, apontando para o ingresso em diferentes ramos de negócios. Procurou-se, também, de forma ativa, estabelecer agências e empresas-âncoras, além do agenciamento do empreendedorismo e dos micronegócios. Projetos de desenvolvimento da produção local foram promovidos, com destaque para a comercialização e a demarcação de marcas regionais (PREFEITURA, 2010).

No que se refere a alguns aspectos demográficos, a população da cidade, segundo cálculo do IBGE de 2019, é de 409.341 habitantes (IBGE, 2019). O Índice de Desenvolvimento Humano Municipal (IDH-M) de Montes Claros é avaliado como alto pelo Programa das Nações Unidas para o Desenvolvimento (PNUD). Seu valor é de 0,770 , sendo 227 o maior de todo o Brasil (entre 5.565 municípios). A cidade apresenta a maioria dos indicadores médios e semelhantes aos da média nacional, conforme o PNUD (ATLAS, 2013).

Por meio do cenário apresentado, identifica-se a importância econômica, social e cultural da cidade de Montes Claros, já que configura um importante centro urbano no Norte do estado 
de Minas Gerais, trazendo, assim, novos hábitos e práticas de outras culturas, em destaque: os esportes e divertimentos.

\section{RESULTADOS}

\section{Delineamento histórico e sociocultural da prática do Badminton em Montes Claros}

No dia 4 de novembro de 1994, foi registrada a Confederação Brasileira de Badminton ( $C B B d$ ). A primeira medalha brasileira foi conquistada em 2007, nos Jogos Pan-Americanos do Rio de Janeiro. A partir daí, essa conquista despertou o interesse do professor de Educação Física Eduardo Lee Murça, o qual, juntamente com Fúlvio Vieira Andrade, fundou a Associação de Badminton de Montes Claros, Minas Gerais (ABdMOC), ao lado, ainda, de outros dez sócios-fundadores que já praticavam o esporte como forma de lazer no Condomínio Monte Olimpo, na cidade.

Por conseguinte, indícios oficiais e registrados sugerem que as iniciativas elementares dessa prática esportiva de raquete e petecas ocorreram na quadra do referido residencial, com uma marcação e um balizamento ainda improvisados, jogando-se sob o sol e à mercê do vento. Ao procurar por abrigo do sol, os jogos passaram a ocorrer na quadra coberta de uma instituição pública de ensino superior, localizada a pequena distância do residencial (ABdMOC, 2020).

Nesse grupo, encontrava-se Eduardo Lee Murça, o qual, como professor de uma escola municipal de Montes Claros, passou a tentar, desde o início de 2016, popularizar o esporte pela cidade. Seu interesse e a adesão ao badminton emergiram justamente em 2007, por ocasião dos Jogos Pan-Americanos do Rio de Janeiro, de que participou como voluntário. Em consonância com o que o educador relata:

[...] para quem tem a oportunidade de assistir ao badminton, verificará que se trata de um esporte contagiante. Ao assistir a uma partida pela primeira (JAEL, 2016).

Após essa experiência, o docente passou a estudar o esporte e a ministrar aulas a respeito dessa atividade. Contudo, ele enfrentou dificuldades ao procurar ensinar uma nova prática esportiva, as quais ele buscou contornar por meio de boa vontade e criatividade. Trata-se, em especial, da dificuldade de ter acesso aos materiais necessários para a prática (raquetes e peteca). $\mathrm{Na}$ falta da obtenção de novos kits de materiais, o professor improvisou com materiais alternativos, como: cabides, meias, garrafas pet e balões (JAEL, 2016).

A Associação de Badminton de Montes Claros (ABdMOC), em paralelo, alcançou o âmbito escolar: disseminou a prática em escolas da cidade e realizou as demarcações das quadras na região dos bairros Augusta Mota, Edgar Pereira, Jardim Brasil e Planalto, expandindo a prática na região, ampliando, então, o acesso a este esporte de alunos de vulnerabilidade social, comunidade e praticantes em geral, o que proporcionou maior interação social e aplicação de condutas morais e de cidadania. Foi possível prestar, assim, um suporte a professores que buscavam trabalhar com a modalidade na escola (ABdMOC, 2020). Nesse sentido, em conformidade com Marques (2007), o esporte, como lazer, transmite valores que possibilitam formar e educar, ressignificando necessidades e possibilidades dos praticantes.
Destarte, 217 anos depois da manifestação dessa prática esportiva na Índia, o badminton chegou à referida cidade do Norte de Minas. Em seguida, ocorreu a criação da Equipe de badminton da Associação Atlética Banco do Brasil (AABB), com um caráter esportivo competitivo, resultando na contribuição para o desenvolvimento da atividade na região. As fontes possibilitaram verificar a constante mudança de significado do esporte em diferentes épocas, tendo este, por vezes, um sentido competitivo, de lazer, educacional ou o paradesportivo. É lícito enfatizar que o badminton, no contexto competitivo norte-mineiro, apresenta, ainda, um aspecto ímpar, que é a incorporação da prática do parabadminton. Em uma perspectiva da inclusão de pessoas com alguma necessidade especial, passa a contar, inclusive, com paratletas (EDUCAMOC, 2019).

Na cidade de Montes Claros, ressaem, em geral, três vertentes: a prática do badminton como lazer; a prática de cunho competitivo e empresarial, ou seja, como propaganda, fazendo parte de um processo de marketização, unindo a paixão pelo esporte e o entretenimento; e a do esporte no contexto da educação física escolar.

As associações desportivas de badminton de Montes Claros, em curto espaço de tempo, conquistaram premiações. Os atletas norte-mineiros colecionam conquistas, sobretudo medalhas e títulos, como apresenta a reportagem: "Voltamos para casa com 12 medalhas de ouro, 10 medalhas de prata e 13 medalhas de bronze, uma conquista surpreendente para a nossa equipe de badminton" (BADMINTON, 2020). Sob a ótica desse cenário, analisamos a difusão do badminton como esporte de alto rendimento por meio das conquistas que os atletas de Montes Claros alcançaram dentro desta década.

Diante disso, pode-se observar que o badminton apresentou uma difusão lenta, porém notável e de importância, como uma prática esportiva que se encontra presente na sociedade de Montes Claros desde o alto rendimento até o esporte como uma prática de divertimento no tempo disponível dos montes-clarenses. Assim, ao estrear no contexto escolar, essa atividade exibe uma expressiva importância por ressignificar a presença de um esporte de origem oriental, adentrando num contexto de hegemonia dos esportes, como futebol, futsal, voleibol, basquetebol e handebol.

\section{Possibilidade de ensino no contexto da educação física escolar em Montes Claros}

Em sua terceira vertente, o esporte é apropriado pelos docentes de Educação Física Escolar. De acordo com a Base Nacional Comum Curricular (BNCC), o badminton faz parte dos esportes de rede, ou quadra dividida, ou parede de rebote (BRASIL, 2018), e o conteúdo encontra-se entre as unidades temáticas que são orientadas para serem desenvolvidas nos anos finais do Ensino Fundamental.

Nesse intento, a Secretaria Estadual de Educação de Minas Gerais reporta um curso de qualificação para a atuação dos professores de Educação Física da rede estadual de educação:

\footnotetext{
Regional de Ensino (SRE) de Montes Claros sobre o Badminton na escola. A ação é resultado de una parceria entre a Secretaria de Estado de Educação (SEE) e o Instituto Peninsula e foi realizada por meio do Programa Impulsiona. A iniciativa tem como objetivo estimular o uso do esporte como ferramenta educacional no desenvolvimento integral dos alunos. (PROFESSORES..., 2019)
} 
Desse modo, professores da rede municipal de Montes Claros, bem como professores da rede estadual de Minas Gerais, tiveram acesso ao workshop e a cursos de badminton na cidade, no período de 2018 e 2019, com o intuito de se inserirem no esporte e terem conhecimentos técnicos e táticos, possibilitando novos olhares sobre a prática na região. Cabe ressaltar que o badminton, no contexto escolar, promove benefícios físicos e sociais, como organização espacial, coordenação óculo-manual, equilíbrio, lateralidade, melhoria da participação dos alunos nas aulas de Educação Física de uma forma global, inclusive para alunos com alguma deficiência (GONÇALVES, 2017).

A prática do esporte no contexto escolar encontra-se ainda em fase de introdução pelos órgãos competentes. Todavia, destaca-se a inserção do badminton nos Jogos Escolares de Minas Gerais (JEMG), durante os quais, a participação de estudantes-atletas, representantes de inúmeras escolas do estado de Minas Gerais, constitui um salto no que tange à disseminação da prática no âmbito escolar, tendo em vista que mais de $160 \mathrm{mil}$ estudantes-atletas, 8 mil professores e cerca de 500 mil espectadores, além de 16 mil profissionais, têm estado envolvidos. (JEMG, [ s.d]).

Há, assim, uma tentativa insistente pelos dirigentes das associações esportivas, como evidencia a reportagem: "existe há três anos e atualmente conta com 38 atletas. A ideia de praticar o esporte já tem se expandido para várias instituições de ensino na cidade" (GOMES, 2018). Apesar de uma falta de apropriação ampla pelos montes-clarenses, existe um esforço para a assimilação do esporte, que compõe um conteúdo do currículo previsto pela BNCC. Portanto, o badminton, em geral, tem alcançado uma tímida adesão das cidades de médio porte, como é caso de Montes Claros; entretanto, percebe-se que ocorre um processo de difusão da prática no âmbito escolar (EDUCAMOC, 2018).

Por intermédio de cursos e workshops realizados pelos órgãos da educação nas redes municipal e estadual, os professores recebem um aporte teórico e prático do esporte, o que serve como elo entre os docentes e as novas práticas. $O$ educador torna-se capacitado, abrindo um leque de possibilidades para os discentes por meio de descobertas guiadas sobre o esporte (ABURACHID et al., 2019).

\section{CONCLUSÃO}

Perante este trabalho de cunho historiográfico e dos documentos impressos e digitais como fonte de informações para a consolidação da investigação, foi possível abalizar estas considerações finais, com alicerce no objetivo proposto de Investigar a emergência da prática esportiva do badminton na cidade de Montes Claros, localizada no Norte de Minas Gerais, desde as suas primeiras manifestações até a sua ascensão na cidade. Diante de limitações da pesquisa, sugere-se, para estudos futuros, a adição de fontes de diferentes naturezas, como as fontes orais, ampliando-se, assim, as possibilidades de interpretação e compreensão da prática na região de Montes claros. Por meio da constituição e da concretização do estudo, foram identificados muitos sinais da emergência e da expansão do badminton em Montes Claros, bem como do quanto esta atividade corporal e cultural ampliou-se no transcorrer de poucos anos na cidade e na região, adquirindo importância no cenário estadual. Desvelaram-se, ainda, importantes colaboradores que improvisa- ram e permanecem buscando o crescimento e a valorização da prática, apresentando, cada um, um amplo valor na narrativa histórica desse exercício na cidade.

Pode-se citar que o presente esporte esteve associado, em um primeiro momento, aos megaeventos esportivos, como os Jogos Paralímpicos de 2016, tendo suas relações estabelecidas com um profissional de Educação Física. Este foi um dos que, segundo o estudo, apresentou responsabilidade pela emergência da prática no contexto de Montes Claros, haja vista que desenvolveu significativas relações com determinadas instituições de lazer, como os clubes, e a difusão através do contexto escolar. A prática do badminton mostrou constante mudança dos seus significados, propiciando uma análise das relações estabelecidas na sociedade e de como o esporte é de suma importância para o retrato de interesses e comportamentos. Logo, por meio da história do esporte, é possível proporcionar novos olhares, não apenas de forma descritiva, acerca de um contexto local e regional. $\mathrm{O}$ estudo ainda possibilitou verificar o crescimento e o desenvolvimento da prática esportiva do badminton em Montes Claros em variadas vertentes, seja de cunho competitivo, seja de lazer, a qual, segundo Mascarenhas, (2005), embasa-se em mudanças econômicas, políticas e sociais. Além disso, identificou-se uma dimensão empresarial.

Destacou-se, também, o cenário de introdução do badminton na Educação Física Escolar. Nesse contexto educacional, a prática imprime seus primeiros passos, visto que faz parte da Base Nacional Comum Curricular (BNCC), que orienta todos os outros currículos dos estados e dos munícipios no que se refere ao contexto escolar. Embora ainda se mostre no início, a prática já é considerada um importante caminho, desde sua introdução no contexto social de Montes Claros até sua materialização no contexto escolar, figurando como uma das novas possibilidades de ensino-aprendizagem na Educação Física Escolar. Por conseguinte, este estudo representa um importante passo para a apreensão de uma versão da história do badminton em Montes Claros tanto para a(o)s pesquisadoras(es) deste campo científico quanto para a sociedade como um todo. A pesquisa permitiu reafirmar a relevância de práticas esportivas inovadoras, como o badminton, em prol de benefícios, em uma esfera social, cognitiva e motora, para os estudantes.

\section{REFERÊNCIAS}

AABB. Associação Atlética Banco do Brasil - Montes Claros. Notícias. Badminton. Montes Claros. 2020. Disponível em: <https://www.aabbmontesclaros.com.br/site/noticia-detalhe/badminton> Acessado em: 17 de março de 2020.

ABdMOC. Associação de Badminton de Montes Claros. Histórico. O começo. Disponível em: <https://www.abdmoc.org/\#bg1>. Acesso em: 23 março de 2020.

ABdMOC. Associação de Badminton de Montes Claros. Projetos: Ação badminton. Disponível em: <http://www.abdmoc.org/>. Acessado em: 24 de março de 2020

ABURACHID, L. M. C.; RIBAS, S.; ARAÚJO, N. D.; GRECO, P. J. Badminton: teaching possibilities in a context of physical education classes at school. Journal of Physical Education, Maringa, v. 30, n. 1, p. 1-12, 2019.

ATLAS DO DESENVOLVIMENTO HUMANO. Ranking decrescente do IDH-M dos municípios do Brasil. Programa das Nações Unidas para o Desenvolvimento (PNUD). Disponível em: <https://web.archive.org/ web/20140708233352/http://www.pnud.org.br/arquivos/ranking-idhm-2010.pdf>. Acesso em: 23 março de 2020.

BACELLAR, C. Uso e mau uso dos arquivos. In: PINSKY, C. B. (Org.). Fontes históricas. São Paulo: Contexto, 2008. 
BARROSO, A. L. R.; DARIDO, S. C. Escola, educação física e esporte: possibilidades pedagógicas. Revista Brasileira de Educação Física, Esporte, Lazer e Dança, São Paulo. v. 1, n. 2, p. 101-14, 2006.

BRASIL. Lei $\mathrm{n}$ 9 9.394, de 20 de dezembro de 1996. Estabelece as Diretrizes e Bases da Educação Nacional. Diário Oficial da União, Brasília, DF, v. 134, n. 248, 23 dez. 1996. Seção 1. Disponível em: <https://www2.camara.leg.br/ legin/fed/lei/1996/lei-9394-20-dezembro-1996-362578-publicacaooriginal-1-pl.html>. Acessado em: 10 de março de 2020.

CBBd. Confederação Brasileira de Badminton. A história do badminton. 2015. Disponível em: <http://www.badminton.org.br/historiadobadmin ton>. Acessado em: 10 de março de 2020.

CBBd. Confederação Brasileira de Badminton. Notícias. Minas Gerais se filia à CBBd e se torna a 20a entidade federada no país. 01/08/2019. Disponíve em: <https://www.badminton.org.br/noticia/4024/minas-gerais-se-filia-a-cbbd-e-se-torna-a-20a-entidade-federada-no-pais/>. Acessado em: 23 março de 2020.

CORRÊA, M. M L F FREITAS, T. C. R. SILVA S. A O ensino dos esportes de raquete no ambiente escolar. Caderno de Educação Física e Esporte, Marechal Cândido Rondon, v. 17, n. 1, p. 309-16, 2019.

DELGADO, L. A. N; FERREIRA, M. M. História do tempo presente e ensino de História. Revista História Hoje, São Paulo, v. 2, n. 4, p. 19-34, 2014.

EDUCAMOC. Secretaria Municipal de Educação de Montes Claros. O portal da Secretaria de Educação de Montes Claros. Alunos de Montes Claros participam mais uma vez dos Jogos Escolares Paraolímpicos de Minas Gerais, 2019. Disponível em: <http://educamoc.com.br/portal/home/noticia/ alunos de montes claros participam mais uma vez dos jogos escolares paralimpicos de minas gerais?ajuda $=256>$. Acessado em: 24 de março de 2020.

EDUCAMOC. Secretaria Municipal de Educação de Montes Claros. Professores de Educação Física das escolas da Prefeitura participam de curso de badminton, 2018. Disponível em: <http://www.montesclaros.mg.gov.br/ agencia noticias/2018/mai18/not0205181292.php>. Acessado: 24 de março de 2020.

GINZBURG, C. Mitos, emblemas, sinais: morfologia e história. São Paulo: Companhia de Letras, 1989.

GOELLNER, S. V.; REPPOLD FILHO, A.; FRAGA, A. B.; MAZO, J. Z.; STIGGER M. P.; MOLINA NETO, V. Pesquisa qualitativa na Educação Física Brasileira: marco teórico e modos de usar. Revista da Educação Física, Maringa. v. 21, n. 3, p. 381-410, 2010.

GOMES, N. "12 Horas de Badminton" acontece neste sábado e visa promover esporte no Norte de MG. Globo Esporte, 2018. Disponível em: <https:/ globoesporte.globo.com/mg/grande-minas-vales/noticia/12-horas-de-badminton-acontece-neste-sabado-e-visa-promover-esporte-no-norte-de-mg. ghtml>. Acesso em: 17 de março de 2020.

JAEL, N. In: Inter Tv Grande Minas. Badminton em Montes Claros. 2016 Disponível em: <http://g1.globo.com/mg/grande-minas/intertvnoticia-grandeminas/videos/t/edicoes/v/em-montes-claros-professor-de-badminton-incentiva-a-pratica-do-esporte-na-cidade/5224416/>. Acesso em: 24 março 2020.

JEMG. Jogos Escolares de Minas Gerais. Jogos Escolares - Esportes, MG. Disponível em: <http://jogosescolares.esportes.mg.gov.br/jemg/>. Acesso em: 24 de março de 2020.

JUNIORS, W. História do Badminton. Tudo sobre Badminton - Origem, história, regras e fundamentos. Disponível em: <https://escolaeducacao.com. br/badminton/>. Acesso em: 24 de março de 2020.

$\mathrm{KATH}$, I. O badminton no ensino fundamental: uma possibilidade pedagógica. In: Cadernos PDE (Orgs.). Os desafios da escola pública paranaense na perspectiva do professor PDE. Secretaria Estadual de Educação, Paraná v. 2, 2014.

MACHADO, M. A. de O.; SOUZA, R. R. de; SILVA, S. A. da. Esportes de raquete, motivação, divulgação e infraestrutura: influências sobre a prática. Caderno de Educação Física e Esporte, Marechal Cândido Rondon, v. 17, n. 2, p. 177-83, 2019.

MARQUES, R. F. R.; ALMEIDA, M. A. B.; GUTIERREZ, G. L. Esporte: um fenômeno heterogêneo: estudo sobre o esporte e suas manifestações na sociedade contemporânea. Movimento, Porto Alegre, v. 13, n. 3, p. 225-42, 2007.

MASCARENHAS, F. Entre o ócio e o negócio: teses acerca da anatomia do lazer. 2005. 308f. Tese (Doutorado em Educação Física) - Universidade Estadual de Campinas, Campinas, 2005.

MELO, V. A. de; BITTENCOURT, M. Uma história do esporte para um país esportivo. Revista Tempo, Niterói, v. 19, n. 34, p. 1-4, 2013.

MELO, V. A. de; FORTES, R. História do esporte: panorama e perspectivas.
Fronteiras: Revista de História, Dourados, v. 12, n. 22, p. 11-35, 2011.

OLIVEIRA, A. R.; GONCCALVES, A. G.; SEABRA JUNIOR, M. O. Badminton e esporte adaptado para pessoas com deficiência: revisão sistemática da literatura. Revista da Associação Brasileira de Atividade Motora Adaptada, Marília, v. 18, n. 1, p. 93-108, 2017.

PIMENTEL, A. O método da análise documental: seu uso numa pesquisa historiográfica. Caderno de Pesquisa, São Paulo, n. 114, p. 179-95, 2001.

SOUZA, A. A.; RAASCH, R. N. H.; MARIA, A. L. Badminton: um diferencial nas aulas de educação física escolar. Acta Brasileira do Movimento Humano, Paraná, v. 7, n. 3, p. 93-108, 2017.

SOUZA, L. D.; SILVA, M. M. e; MOREIRA, T. S. O perfil da produção científica online em português relacionada às modalidades olímpicas e paraolímpicas. Movimento, Porto Alegre. v. 22, n. 4, p. 1105-20, 2016.

\section{AGRADECIMENTOS}

Os autores agradecem ao Programa Institucional de Iniciação Científica Voluntária - ICV da Coordenadoria de Iniciação Científica da Pró-Reitoria de Pesquisa da Universi-dade Estadual de Montes Claros (Unimontes).

\section{CONFLITO DE INTERESSE}

Os autores do estudo declaram não haver conflito de interesses.

\section{ORCID E E-MAIL DOS AUTORES}

Emilly Thais Gonçalves Dias (Autor Correspondente)

ORCID: 0000-0002-3946-5636.

E-mail: emillythais.moc@gmail.com

Guilherme Carvalho Vieira

ORCID: 0000-0001-7949-4530.

E-mail: guivieira9988@gmail.com

Ester Liberato Pereira

ORCID: 0000-0001-6193-9132.

E-mail: ester.pereira@unimontes.br 